2 Hook EB. Exclusion of chromosomal mosaicism: tables of $90 \%$. $95 \%$, and $99 \%$ confidence limits and comments on use. Am J Hum Genet 1977:29:94-7.

${ }^{3}$ Feingold M, Atkins L. A case of trisomy 9. J Med Genet 1973:19:184-7.

4 Francke U, Benirschke K, Jones OW. Prenatal diagnosis of trisomy 9. Humangenetik 1975:29:243-50.

s Sutherland GR, Carter RF, Morris LL. Partial and complete trisomy 9: delineation of a trisomy 9 syndrome. Hum Genet 1976;32:133-40.

- Seabright M. Gregson N, Mould S. Trisomy 9 associated with an enlarged 9qh segment in a liveborn. Hum Genet 1976;34:3235.

7 Annerén G. Sedin G. Trisomy 9 syndrome. Acta Paediatr Scand 1981;70:125-8.
${ }^{8}$ Mantagos S. McReynolds JW. Seashore MR. Breg WR. Complete trisomy 9 in two liveborn infants. J Med Genet 1981:18:377-82.

" Frohlich GS. Delincation of trisomy 9. J Med Genet 1982:19:316-8.

${ }^{10}$ Birth Statistics. Review of the Registrar General on births and patterns of family building in England and Wales 1981. Office of Population Censuses and Surveys. London: HMSO, 1984.

Correspondence and requests for reprints to Dr I D Young, Department of Child Health, Clinical Sciences Building, Leicester Royal Infirmary, PO Box 65, Leicester LE2 7LX.

\title{
Phenotypic delineation of ring chromosome 15 and Russell-Silver syndromes
}

\author{
GOLDER N WILSON, SUE ELLYN SAUDER, MARK BUSH, AND \\ INESE Z BEITINS \\ Department of Pediatrics and Communicable Diseases, C S Mott Children's Hospital, The University of \\ Michigan, Ann Arbor, Michigan 48109, USA.
}

SUMMARY A male child with features of the Russell-Silver syndrome, including pre- and postnatal growth delay, triangular facies, bilateral fifth finger clinodactyly, and disproportionate lower extremities, was found to have a ring chromosome 15 in all peripheral leucocytes examined. Review of the reported cases of ring chromosome 15 defines a malformation syndrome with a characteristic facies related to deletion of the $15 q 26 \cdot 2 \rightarrow$ qter region. RussellSilver and ring 15 syndromes share clinical features such as growth deficiency, triangular facies, digital anomalies, and café-au-lait spots. Microcephaly, mental retardation, facial dysmorphology, limb anomalies, and cardiac defects are more striking in ring chromosome 15 patients and are indications for karyotyping when found in conjunction with the RussellSilver phenotype.

Since the original reports of Silver et $a l^{1}$ and Russell, ${ }^{2}$ a characteristic syndrome of intrauterine growth retardation, postnatal growth delay, and dysmorphic features has been delineated in over 150 reported cases. ${ }^{3-5}$ Minor anomalies associated with

Received for publication 10 July 1984. Accepted for publication 2 August 1984.
Russell-Silver dwarfism include a triangular facies, downturned corners of the mouth, fifth finger clinodactyly, skeletal asymmetry, and café-au-lait spots. We report here a patient with ring chromosome 15 who was initially diagnosed as having Russell-Silver syndrome. Review of 22 cases of ring chromosome 15 defines a clinical syndrome which is similar but distinct from that of Russell-Silver dwarfism.

\section{Case report}

The proband was the term product of an uncomplicated gestation to a 20 year old primigravida with a $6.8 \mathrm{~kg}$ weight gain. The father was 22 and the family history was unremarkable. Birth weight was $2.51 \mathrm{~kg}$ ( 3 rd centile), and length $44 \mathrm{~cm}$ ( $<3$ rd centile). Tachypnoea developed at the age of six hours owing to a small patent ductus arteriosus and treatment with digoxin was started. Following an otherwise uneventful neonatal course, there was no further sign of cardiac disease and digoxin was discontinued. Right equinovarus and left metatarsus adductus anomalies were also noted at birth and treated with serial casting. Proportionate short stature with decreased growth velocity was noted during the first two years and evaluated at $31 / 2$ and 4 years 7 months. Physical examination at 4 years 7 months revealed a height of $84 \mathrm{~cm}$ (50th centile for 18 months), a weight of $8.9 \mathrm{~kg}$ (50th centile for 8 
months), and a head circumference of $47 \mathrm{~cm}$ (50th centile for 12 months). The facies (fig 1) were triangular with mild hypertelorism (interpupillary distance $4.8 \mathrm{~cm} ; 50$ th centile for $21 / 2$ years). The ears were large with a hypoplastic antihelix. The mouth was small with downturned corners and normal dentition. There was no cardiac murmur. There was bilateral clinodactyly of the fifth fingers with single digital crease and bilateral single palmar creases. Dermatoglyphs were unremarkable except for tented arch patterns on the right second and left second and fifth digits. The right leg was thinner and shorter than the left $(36$ versus $37 \mathrm{~cm}$ ). The second toe was anteriorly placed bilaterally. Developmentally, the patient had normal motor milestones but a delay in speech.

Laboratory studies showed normal thyroxine, growth hormone, and somatomedin $\mathrm{C}$ concentrations at $3 \frac{1}{2} 2$ years; the bone age was 2 years. At 4 years 7 months the bone age was 2 years 8 months and growth velocity was $4 \mathrm{~cm}$ per year. Provocative testing with L-dopa and insulin induced hypoglycaemia showed normal growth hormone and cortisol responses. A peripheral leucocyte karyotype using standard Giemsa-trypsin banding methods showed a $46, X Y, r(15)$ karyotype in all 25 cells examined (fig 2). No evidence of further rearrangements or
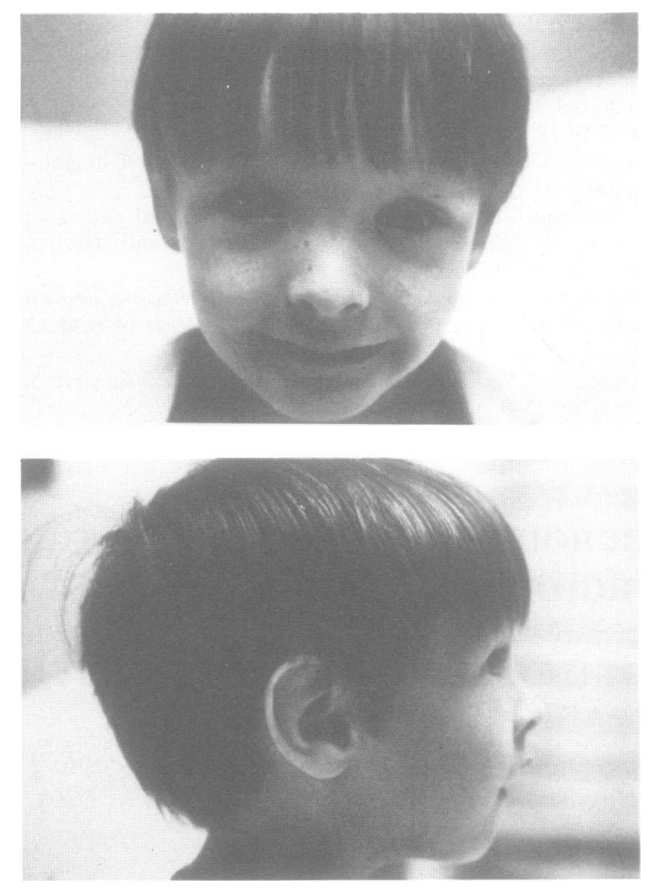

FIG 1 Frontal and lateral views of the proband.
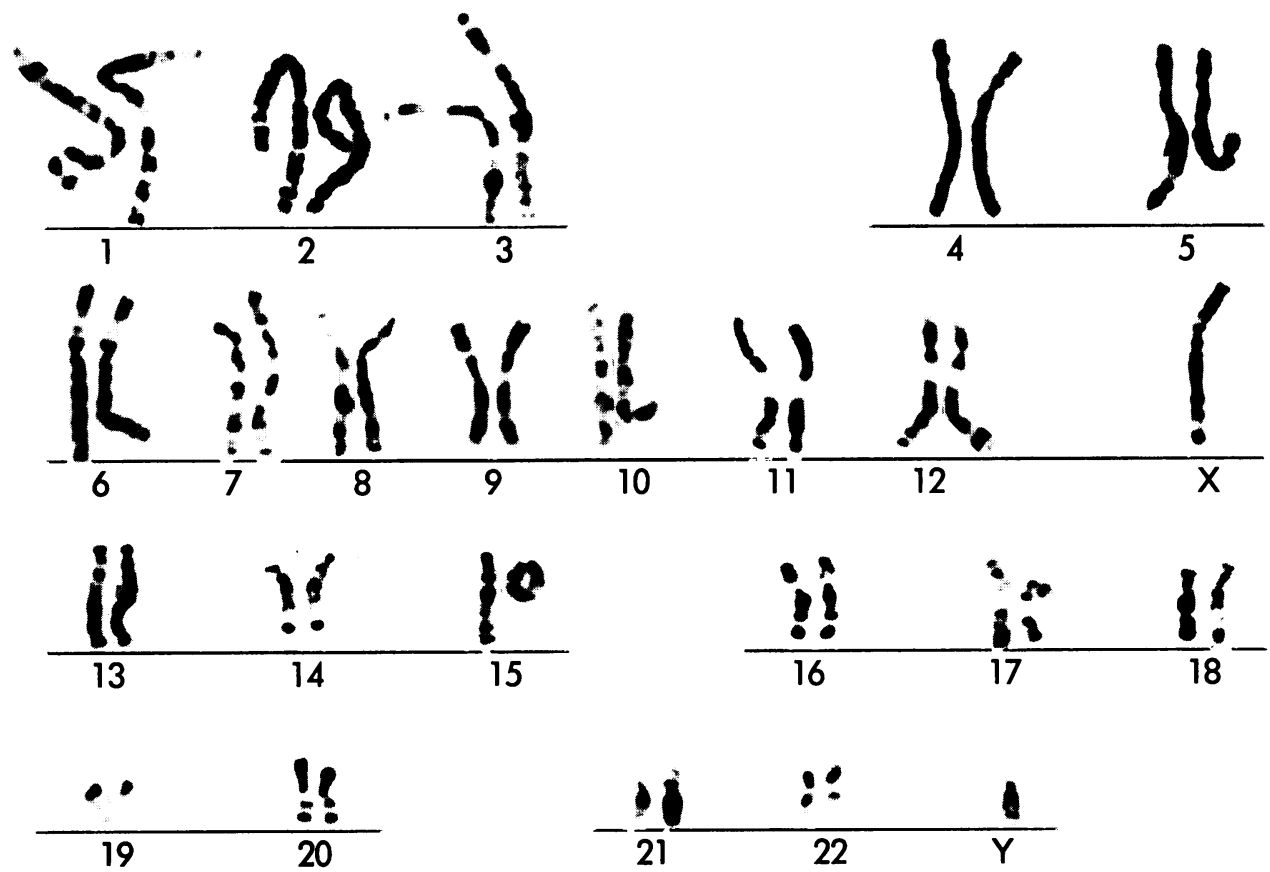

FIG 2 Giemsa-trypsin banded karyotype from the proband showing 46,XY,rI5. 
instability of the ring chromosome could be found. Breakpoints at band p11 of the short arm and q26.2 of the long arm were interpreted as the sites of ring formation. Staining for nucleolus organiser regions ${ }^{6}$ was positive for the normal chromosomes 15 in the parents and child but negative for the ring chromosome 15 .

\section{Results and discussion}

We describe a patient with pre- and postnatal growth delay, triangular facies, hypertelorism, clinodactyly, limb asymmetry, and mild developmental retardation due to deletion of chromosome 15 as a result of ring formation. Standard Giemsa-trypsin and nucleolus organiser staining indicated the deletion could only involve the 15 short arm and long arm termini. Since the short arm terminus is thought to consist of satellite DNA sequences, we would presume that the deletion region responsible for this phenotype is the chromosome 15 long arm terminus distal to band 32. Rearrangements often associated with ring chromosomes were not detected in our patient.

Although some patients with ring chromosome 15 have minimal dysmorphism, ${ }^{7-9}$ the summary in the table defines a clinical ring 15 syndrome with growth deficiency and a characteristic malformation pattern. Certain ring 15 cases, such as the proband and the patients of Rumenic et al, ${ }^{12}$ Ferrante et al, ${ }^{13}$ and Yunis et $a l,{ }^{14}$ have a distinctive triangular facies with frontal bossing, hypertelorism, and downturned corners of the mouth. Predominance of females, advanced parental age, microcephaly with mental retardation, café-au-lait spots, and limb anomalies are additional features of ring 15 syndrome. Phenotypic variability undoubtedly reflects in part the different extents of chromosome deletion, ${ }^{15}$ ring instability, ${ }^{12}$ or mosaicism $^{16}$ which have been reported.

The table also presents the clinical features of Russell-Silver syndrome, listed as a mean percentage of cases taken from three separate surveys. ${ }^{3-5}$ Since the triangular facies and certain other characteristics may not be recognised during infancy, the average age of Russell-Silver patients at the time of publication (6.2 years) was compared to ring chromosome 15 patients ( 9.6 years). Both syndromes have a striking incidence of pre- and postnatal growth deficiency, advanced parental ages, triangular facies with frontal bossing, downturned corners of the mouth, digital anomalies such as clinodactyly, cryptorchidism/hypospadias in the male, and café-au-lait spots. Ring chromosome 15

TABLE Comparison of ring chromosome 15 and Russell-Silver syndromes.

\begin{tabular}{|c|c|c|c|c|c|c|c|c|}
\hline & \multirow{2}{*}{$\begin{array}{l}\text { Ring } \\
\text { chromosome }\end{array}$} & \multirow{2}{*}{15} & \multicolumn{6}{|c|}{ Russell-Silver syndrome } \\
\hline & & & Mean & $\begin{array}{l}\text { Marks and } \\
\text { Bergeson }\end{array}$ & & $\begin{array}{l}\text { Escobar } \\
\text { et ol }\end{array}$ & $\begin{array}{l}\text { Marietta } \\
\text { et al }\end{array}$ & \\
\hline No of cases & 22 & & & 148 & & 90 & 126 & \\
\hline Average age (y) & $9 \cdot 6$ & & $6 \cdot 2$ & & & & $6 \cdot 2$ & \\
\hline Maternal age $(y)$ & 28.9 & & $27 \cdot 5$ & & & & $27 \cdot 5$ & \\
\hline \multirow[t]{2}{*}{ Paternal age $(y)$} & $31 \cdot 7$ & & $30 \cdot 2$ & & & & $30 \cdot 2$ & \\
\hline & Fraction & $(\%)$ & $(\%)$ & Fraction & $(\%)$ & $(\%)$ & Fraction & $(\%)$ \\
\hline Female sex & $15 / 22^{*}$ & $(68)$ & (41) & $52 / 121$ & (43) & - & $48 / 126$ & (38) \\
\hline Low birth weight $\dagger$ & $15 / 20$ & (75) & (96) & $95 / 96$ & (99) & - & $113 / 122$ & (93) \\
\hline Short stature ${ }^{\circ}$ & $22 / 22$ & $(100)$ & (98) & $143 / 147$ & (98) & - & - & \\
\hline Microcephalyt & $19 / 20$ & (95) & (27) & & & & $15 / 56$ & (27) \\
\hline Triangular facies & $8 / 19$ & (42) & (83) & - & & $(8.3)$ & - & \\
\hline Frontal bossing & $7 / 18$ & (39) & (46) & $38 / 148$ & (26) & $(65)$ & & \\
\hline Hypertelorism & $9 / 19$ & (47) & & & & & & \\
\hline Cleft/high palate & $3 / 22$ & (14) & $(10)$ & $7 / 148$ & $(4 \cdot 7)$ & (16) & & \\
\hline \multicolumn{9}{|l|}{ Downturned } \\
\hline corners of mouth & $9 / 19$ & (47) & (59) & $63 / 148$ & (43) & (74) & & \\
\hline Anomalous ears & $6 / 22$ & (27) & (20) & & & (20) & & \\
\hline Digital anomaly $\dot{\ddagger}$ & $14 / 22$ & (64) & $(78)$ & & & $(80)$ & & $(75)$ \\
\hline Limb anomaly & $6 / 22$ & (27) & (13) & $6 / 148$ & $(4 \cdot 0)$ & (22) & & \\
\hline Skeletal asymmetry & $2 / 22$ & $(9 \cdot 1)$ & (66) & $85 / 148$ & $(57)$ & (74) & & $(68)$ \\
\hline \multicolumn{9}{|l|}{ Cryptorchidism/ } \\
\hline hypospadias & $2 / 6$ & (33) & & $34 / 69$ & $(49)$ & $(32)$ & $16 / 73$ & (22) \\
\hline Renal anomalies & $2 / 20$ & (10) & $(7 \cdot 0)$ & $9 / 148$ & $(6 \cdot 1)$ & $(7.9)$ & & \\
\hline Cardiac anomalies & $5 / 22$ & (23) & $(4 \cdot 7)$ & $7 / 148$ & $(4 \cdot 7)$ & & & \\
\hline Café-au-lait spots & $5 / 19$ & (26) & & $15 / 148$ & $(10)$ & $(28)$ & & (16) \\
\hline Mental retardation & $21 / 21$ & $(i(x))$ & $(20)$ & $16 / 121$ & (18) & & & (28) \\
\hline
\end{tabular}

Ring 15 patients are from the summary of Moreau and Teyssier ${ }^{10}$ with the addition of the proband and the case of Fryns $e$ al. ${ }^{11} *$ Denominator reflects those cases in which the feature was specifically mentioned or, in the judgement of the authors, was demonstrated or excluded. + Defined as below the 3 rd centile. $\ddagger$ Clinodactyly, short, or fusiform digits. § Congenital hip dislocation, equinovarus, calcaneovalgus. 
patients are predominantly female with a higher incidence of microcephaly, mental retardation, facial anomalies, limb deformities, and cardiac defects. Russell-Silver patients are predominantly male with an increased incidence of skeletal asymmetry. Endocrinological abnormalities such as growth hormone deficiency and hypopituitarism ${ }^{17} 18$ appear more typical of Russell-Silver syndrome.

Other chromosome abnormalities such as diploid/ triploid mixoploidy, ${ }^{19}$ trisomy 18 mosaicism, ${ }^{20}$ and deletion $18 \mathrm{p}^{21}$ have been reported in patients with the Russell-Silver phenotype. It seems likely that this phenotype is caused by multiple agents which have in common a certain pattern of intrauterine growth retardation. The frequency of asymmetry implies differential effects before laterality is established, as occurs in mosaicism for triploidy ${ }^{19}$ or trisomy 9.22 This report emphasises the need for karyotyping Russell-Silver patients with mental retardation, cardiac defects, or unusual dysmorphology.

\section{References}

1 Silver H, Kiyasu W, George J, Deamer W. Syndrome of congenital hemihypertrophy, shortness of stature and elevated urinary gonadotrophins. Pediatrics 1953;12:368-76.

2 Russell A. A syndrome of 'intrauterine' dwarfism recognizable at birth with cranio-facial dysostosis, disproportionately short arms, and other anomalies (5 examples). Proc $R$ Soc Med 1954;47:1040-4.

${ }^{3}$ Marks LJ, Bergeson PS. The Silver-Russell syndrome. Am J Dis Child 1977;131:447-51.

${ }^{4}$ Escobar V, Gleiser S, Weaver DD. Phenotypic and genetic analysis of the Russell-Silver syndrome. Clin Genet 1978;13:278-88.

5 Marietti G, Mastroiacovo P, Colabucci F, Parenti D, Riccardi R, Currō V. La sindrome di Silver-Russel. Minerva Pediatr 1979;31:41-62.

6 Goodpasture C, Bloom SE. Visualization of nucleolar organizer regions in mammalian chromosomes using silver staining. Chromosoma 1975;53:37-50.

7 Emberger JM, Rossi D, Jean R, Bonnet H, Dumas R. Etude d'une observation de chromosome du groupe 13-15 en anneau $\stackrel{\mathbb{P}}{?}$ (46,XY,15r). Humangenetik 1971;11:295-9.

${ }^{8}$ Forabosco A, Dutrillaux B, Vazzoler G, Lejeunc J. Chromosome 15 en anneau: $\mathrm{r}(15)$. Identification par denaturation 7 menagee. Ann Genet (Paris) 1972;15:267-70.

${ }^{9}$ Stoll C, Juif JG, Luckel JC, Lausecker C. Ring chromosome 15:r(15). Identification by $\mathrm{R}$ banding. Humangenetik 1975;27:259-62.

10) Moreau N, Teyssier M. Ring chromosome 15: report of a case in an infertile man. Clin Genet 1982;21:272-9.

$"$ Fryns JP, Jaeken J, Devlieger H, Debucquoy P, Eggermont E, Van den Berghe H. Ring chromosome 15 syndrome. Acta Paediatr Belg 1981;34:47-9.

12 Rumenic L, Joksimovic I, Anaf M. Ring chromosome 15 in child $\vec{\omega}$ with minor dysmorphism of phenotype. Hum Genet 1976;33:187-8.

13 Ferrante E, Boscherini B, Bruni L, Vignetti P, Finocchi G. La sindrome r(15). Minerva Pediatr 1977;29:2163-8.

14 Yunis E, Leibovici M, Quintero L. Ring (15) chromosome. $\omega$ Hum Genet 1981;57:207-9.

15 Ledbetter DH, Riccardi VM, Au WW, Wilson DP, Holmquist GP. Ring chromosome 15: phenotype, Ag-NOR analysis, O secondary aneuploidy and associated chromosome instability. Cytogenet Cell Genet 1980;27:111-22.

16 Pfeiffer RA, Dhadial R, Lenz W. 46,XX/46,XXr(15) mosaicism. Report of a case. J Med Genet 1977;14:63-5.

17 Hall JG. Microphallus, growth hormone deficiency and hypoglycemia in Russell-Silver syndrome. Am J Dis Child 1978;132: $\vec{\varphi}$ 1149.

18 Draznin MB, Stelling MW, Johanson AJ. Silver-Russell syndrome and craniopharyngioma. J Pediatr 1980;96:887-9.

19 Graham JM Jr, Hoehn H, Lin MS, et al. Diploid-triploid mixoploidy: clinical and cytogenetic aspects. Pediatrics 1981;68:23-8.

20) Chauvel PJ, Moore CM, Haslam RHA. Trisomy-18 mosaicism ڤै with features of Russell-Silver syndrome. Dev Med Child Neurol $\unrhd$ 1975;17:220-43.

21 Christensen MF, Nielsen J. Deletion short arm 18 and SilverRussell syndrome. Acta Paediatr Scand 1978;67:101-3.

22 Wilson GN, Barr M Jr. Trisomy 9 mosaicism: another etiology for the manifestations of Goldenhar syndrome. $J$ Craniofacial Genet Dev Biol 1983;3:313-6.

Correspondence and requests for reprints to $\operatorname{Dr} G_{\stackrel{0}{0}}^{0 .}$ Wilson, Section of Pediatric Genetics, C S Mott 3 Children's Hospital, K2015 Holden, Box 007, Ann Arbor, Michigan 48109, USA. 